\title{
Literature Review on Soft Computing Based Optimization Models
}

\author{
Ms Mani Dublish(Assistant Professor in IMS Noida) \\ Dr Anita Pati(Assistant Professor in IMS Noida) \\ Dr Pankaj Agarwal (Asst Professor in IMS Noida) \\ Dr Shikha Mittal(Assistant Professor in IPEM Ghaziabad)
}

\begin{abstract}
:
Soft computing is the use of approximate computations to give squishy but usable results to complex computational problems. The approach enables results for problems that may be either unattainable or just too time- consuming to break with current tackle. Soft computing is occasionally appertained to as computational intelligence. Soft computing provides an approach to problem- working using means other than computers. With the mortal mind as a part model, soft computing is tolerant of partial trueness, query, imprecision and approximation, unlike traditional computing models. The forbearance of soft computing allows experimenters to approach some problems that traditional computing cannot reuse. Soft computing uses element fields of study in, sense, literacy, Inheritable algorithms, artificial neural networks etc.As a field of fine and computer study, soft computing has been around since the 1990s. The alleviation was the mortal mind's capability to form real- world results to problems through approximation. Soft computing contrasts with possibility, an approach that's used when there isn't enough information available to break a problem. In discrepancy, soft computing is used where the problem isn't adequately specified for the use of conventional calculation and computer ways. Soft computing has multitudinous real- world operations in domestic, marketable and artificial situations.
\end{abstract}

Keyword: Fuzzy Logic, Genetic Algorithm, Artificial neural Network

Introduction: Soft Computing is a emulsion of methodologies that were designed to model and enable results to the real world problems which aren't modeled, or too delicate to model, mathematically. These problems are generally associated with fuzzy, complex, and dynamical systems, with uncertain parameters. Numerous ways, soft computing represents a significant paradigm shift in the points of computing-a shift which reflects the fact that the mortal mind, unlike present day computers, possesses a remarkable capability to store and reuse information which is pervasively squishy, uncertain and lacking in order. Soft computing ways are more important and effective as they give the doable and less expensive results compared to hard computing ways. It's a multi-disciplinary field. Recent developments in lores and computers have led to bettered modeling and understanding of situations in all areas of mortal exertion. In effect, the part model for soft computing is the mortal mind. With the fuzzy sense grounded fashion, imprecision, query and mortal acquainted knowledge 


\section{International Journal of Scientific Research in Engineering and Management (IJSREM)}

representation is possible; still tone literacy and conception of rules can't be possible. There are several styles for soft computing family from which Fuzzy Sense (FL) and Inheritable Algorithm (GA) are the most important

A system grounded on the fuzzy sense known as fuzzy control system. Generally, control systems modeling have been grounded upon the use of fine ways to the model ( input/ affair) relationship of the system in question. Numerous real- world systems still, may not be as readily described mathematically due to the complexity of the factors of the factory and the commerce between them, and accordingly, the model may be subject to certain hypotheticals or conditions. In similar models, the degree of fine perfection needed to fully describe every aspect of the process, is either prohibitive ornon-trivial. In addition, for factual perpetration of similar systems, heuristics, gained through mortal experience, are frequently employed in the tuning of the final regulator. The proper application of space is also a critical element in business world, whether one is a manufacturer, retailer or a wholesaler. Business associations substantially concentrate on perfecting the client services and reduce the force costs in such a manner so that profit can be maximum. Force is the lifeblood for any business associations i.e., it's the biggest asset and frequently inefficiently managed. Force has always been the foundation of conducting business in any association. Holding and managing of an force is essential for effective and smooth handling of any business association be it a manufacturing assiduity, an educational institute, a five star hostel, a sanitarium and a printing press etc. In business association, force operation is one of the major core capabilities to contend in the global request place. The most important purpose served by the stores is to give the continued service to the manufacturing divisions. Supplies represent a substantial portion of the total means of a company and considerable trouble is needed to control the supplies. The purpose of force in any business is to drop the cost of set up and deficit cost. Whenever demands of guests aren't fulfilled also good- will of the guests may be lost and the cancellations of orders i.e., result may be in the lost of business. The only result for that type of problems is the keep of force. The use of Fuzzy Sense has an important operation in the area of control system design where mortal expert knowledge, rather than precise fine modeling, of a process or factory is used to model/ apply the required regulator. The operation of soft computing ways has substantially two important advantages. First, it break then on-linear problems and alternate is introducing the mortal knowledge similar as recognition, literacy, understanding and others field of soft computing. Moment's force control models for time- varying demand lately attracted a great deal of exploration which helps to develop the interest of experimenter in this field. In real life situations, demand isn't constant so take the demand rate is generally in terms of a direct, exponential, quadratic, time- varying, product dependent, multivariate, or some other stock-dependent function.

\section{PRESENT STATE OF KNOWLEDGE}

In real world problem, deterioration of many items such as chemicals, volatile liquids, blood banks, medicines and some other goods during storage period is non-negligible. So, the management and holding of inventories of perishable items becomes an important problem for inventory managers. In the other hand, delayed payment is an important form of financing for businesses in a broad range of industries and economies that extremely well-developed and are being used in financial markets. Furthermore, both inflation and time value of money issues will have main effects in financial markets. All of the above mentioned issues (deteriorating items, delayed payment, inflation and time value of money) are separately regarded in some inventory models. The effective of supply channel inventories is perhaps the most fundamental objective of supply chain 


\section{International Journal of Scientific Research in Engineering and Management (IJSREM)}

management. Manufactures procure raw material and process them in to finished goods, and sell the finished goods to distributors, then to retailer and/or customer, it forms a "multi-echelon "inventory system. A large amount of researches on multi-echelon inventory system has appeared in the literature in the last decades. Soft computing is a fusion of methodologies that were designed to model and enable solutions to the real world problems which are not modeled, or too difficult to model, mathematically. These problems are typically associated with fuzzy, complex, and dynamical system, with uncertain parameters. The study of deteriorating items with inventory model started Ghare and Schradher(1963)[1] who established the inventory model for constant rate of decay. The concept of soft computing techniques first introduced by Zadeh (1965)[2]. The invention of soft computing techniques by the need to represent and capture the real world problems with its fuzzy data due to uncertainty.).In some cases arise when favorable cases are not able to deal with the situation , this term is known as intuitionistic fuzzy sets introduced by Atanassov (1986)[3]. Further two more new operators were introduced by Atanassov (1989)[4] in intuitionistic fuzzy sets theory. Bensoussan et al.(1975)[5] make the inventory models in which deterministic and stochastic deterioration rates were given. Raafat (1991)[6] done the review of published inventory literature for decaying inventory models. Chen (1998)[7] developed an inventory model in which shortages are allowed and fully backordered. Wee (1999)[8] create a deteriorating inventory model with partial backordering when the product in stock deteriorates with time. Because of its features such as intelligent control, non linear programming, optimization, soft computing has become more popular with in people from different areas, Jang et al.(1997)[9].Zadeh(1994)[10] said that soft computing is not a single method ,but it's a mixture of many methods as fuzzylogic,neural network and genetic algorithm. Conventional and soft computing based problem solution is suggested by Kulkarni et al.(1993)[11]. IP et al.(2000)[12] develop a new extensive model to address the multi-product production environment in which genetic algorithm is used to obtain the large scale problem. Liao (2000)[13] proposed an inventory model with deteriorating items under inflation when a delay in payment is permissible. Chung et al.(2001)[14] derives an inventory model for deteriorating items with the demand of linear trend and shortages in consideration of time value of money. Goyal et al.(2001)[15] presents a review of the advances of deteriorating inventory in recent trends in inventory modeling. Zhou (2003)[16] develops a deterministic replenishment model with multiple warehouses one is an owned warehouse and other is rented with storage capacity. Yang et al.(2003)[17] create an integrated multilot-size production inventory model of deteriorating items.Papadrakakis et al.(2003)[18] examines the efficiency of soft computing techniques in structural optimization for solving large scale continuous or discrete structural optimization problems.Balkhi et al.(2004)[19] developed an inventory model for deteriorating items with stock dependent and time-varying demand rates for a finite time planning.Kamiya et al.(2005)[20] developed a fusion of soft computing and hard computing for large scale plants involves numerical trade off such as cost, accuracy, reliability etc. Law et al.(2006)[21] makes an integrated production -inventory model for both the manufacturer and the retailer. The model considered both ameliorating and deteriorating effect taking account of multiple drivers, partial backordering and time discounting.Lo et al.(2007)[22]develops an integrated production- inventory model for assuming a varying rate of deterioration, partial backordering, inflation, imperfect production processes and multiple deliveries.Chakraborty et al.(2008)[23] presents a generalized economic manufacturing quantity model for 


\section{International Journal of Scientific Research in Engineering and Management (IJSREM)}

an unreliable production system in which the production facility may shift from an 'in-control 'state to an 'out-of-control' state at any random time and may ultimately break down afterwards.LI et al.(2008)[24] deal with the uncertainties and randomness of defective percentage and shortages happened in the real-life situations, the order inventory model with a mixture of shortages and imperfect items is presented and investigated in the fuzzy environment.Rong et al.(2008)[25] makes an optimization inventory policy for a deteriorating item with imprecise lead -time, partially/ fully backlogged shortages and price dependent demand is developed under two-warehouse system. Wee et al. (2009) [26] developed a fuzzy multi-objective joint replenishment inventory model of deteriorating items is developed. The model maximizes the profit and return on inventory investment under fuzzy demand and shortage cost constraint. Ko et al.(2010)[27] creates a review of soft computing applications in supply chain management. The aim of this paper is to summaries the findings by a systematic review of existing research paper. Liao et al.(2010)[28] presents an inventory model for optimizing the replenishment cycle time for a single deteriorating item under a permissible delay in payments and constraints on warehouse capacity. Wang et al. (2011)[29] empirically investigates how different deterioration rates in each echelon affect performances of individuals and integrated inventory policies. Singh et al.[2011][30] developed a soft computing model with deterioration and price dependent demand. Bakker et al.(2012)[31] presents an up-to-date review of the advances made in the field of inventory control of perishable items(deteriorating inventory). KumarSett et al.(2012)[32] makes an inventory model of two-warehouse is considered with quadratic ally increasing demand and time varying deterioration. Shah et al.(2013)[33] considers an inventory system with non-instantaneous deteriorating item in which demand rate is a function of advertisement of an item and selling price. This paper aids the retailer in maximizing the total profit by determining optimal inventory and marketing paramenters.Samal et al.(2014)[34] developed an inventory model for minimizing inventory cost, treating the holding and ordering costs and demand as independent fuzzy variables. Singh et al.(2014)[35] findings a systematic review of existing research paper concern with the application of soft computing techniques to inventory management.Talezadeh et al.(2015)[36] develops a vendor Managed inventory (VMI) model for a two - level supply chain comprised of one vendor and several non -computing retailers in which both the raw material and the finished product have different deteriorations rates. Das et al(2015)[37] consists of joint relationship between a manufacturer and multiple markets in which manufacturer offers part-payment to the markets due to their collection of finished products during the production run time.Ibhrahim(2016)[38] gives an overview of the current state of soft computing techniques and describes the advantages and disadvantages of soft computing compared to traditional hard computing techniques. Janssen et al.(2016)[39] give an up-to-date review of perishable inventory models. Chan et al(2017)[40] investigates how production rate affects the total system cost, and develops a solution procedure for finding the optimal production rate for the traditional models. The proposed model also considers deterioration during deliveries, which is usually neglected in the literature of inventory model of deterioration items. Li et al.(2017)[41] aims to deliver a platform, where researchers coming from the usage of concepts of soft computing, report on the linkages between the methodology and practice of optimization, such as software reliability, redundancy optimization, and others. Banerjee et al.(2017)[42] developed and analyzed an inventory model when demand for a deteriorating item depends initially only upon its selling price and later also on the freshness condition. in et al.(2018)[43] proposed model maximizes the 
profit under rent warehouse incentives decreasing over time and price sensitive demands. Braglia et al.(2019)[44] done a continuous review on inventory model for a deteriorating item with random demand and positive lead time.Chandradas et al.(2020)[45] make an inventory model of non-instantaneous deteriorating items is developed with the demand dependent on the selling price of the product.

\section{CONCLUSION:}

This paper presents a review for the application of soft computing techniques like fuzzy logic and genetic algorithms to use for improve the effectiveness and efficiency for various aspect of inventory management. The proposed paper can be used as a guidance to start research in inventory control with soft computing techniques.

\section{References:}

1: Ghare, P.M. and Schrader, (1963). A Model for an Exponential Decaying Inventory. Journal of Industrial Engineering, (14), 238-243.

2: L. A. Zadeh, (1965).Fuzzy sets. Information and control, (8), 338-353.

3: Atanassov,(1986).Intuitionistic Fuzzy sets. Fuzzy sets and systems, (20), 87-96.

4: Atanassov, (1989).More On Intuitionistic Fuzzy sets. Fuzzy sets and systems, (33), 37-45.

5: Alain Bensoussan, Georges Nissen and Charles S.Tapiero,(1975).Optimum Inventory and Product Quality Control with Deterministic and stochastic Deterioration- An application of Distributed Parameter Control systems.IEEE Transactions on automatic control, (20), 407-412.

6: Fred Raafat, (1991). Survey of Literature on Continuously Deteriorating inventory Models, journal of the Operational research Society, (42), 27-37.

7:Jen -Ming Chen(1998). An inventory model for deteriorating items with time-proportional demand and shortages under inflation and time discounting, International Journal of Production Economics,(55),21-30.

8: Hui-Ming Wee (1999).Deteriorating inventory model with quantity discount, pricing and partial backordering, International journal of Production Economics, (59), 511-518.

9: Jang JSR, Sun CT, and Mizutani E.(1997). Neuro Fuzzy and Soft Computing, A Computational Approach to Learning and machine Intelligence

10: L.A Zadeh (1994).Fuzzy Logic, neural networks, and soft computing, Communications of the ACM,(37),77-84.

11:Gupta P,kulkarni N(1993).An introduction of Soft Computing Approach over Hard Computing, International Journal Of Latest Trends. 
12: W.H. Ip, Y. Li, K.F. Man and K.S. Tang (2000). Multi-product planning and scheduling using genetic algorithm approach, Computers \& Industrial Engineering,( 38) ,283-296.

13: Liao (2000). An inventory model with deteriorating items under inflation when a delay in payment is permissible, Int. J. Production Economics, (63), 207-214.

14: Kun-Jen Chung and Sui-Fu Tsai (2000). Inventory systems for deteriorating items with shortages and a linear trend in demand-taking account of time value, Computers \& Operations Research, (28), 915-934.

15: S.K Goyal and B.C .Giri (2001). Recent trends in modeling of deteriotring Inventory, European Journal of Operation Research 134 (2001), 1-16.

16: Yong-Wu Zhou (2003). A multi-warehouse inventory model for items with time-varying demand and shortages, Computers \& Operations Research 30, 2115-2134.

17: Po-Chung Yang, Hui-Ming Wee (2003). An integrated multi-lot-size production inventory model for deteriorating item, Computers \& Operations Research 30,671-682.

18: Manolis Papadrakakis, Nikos D. Lagaros (2003). Soft computing methodologies for structural optimization, Applied Soft Computing 3, 283-300.

19: Zaid T. Balkhia, Lakdere Benkherouf (2004). On an inventory model for deteriorating items with stock dependent and time-varying demand rates, Computers \& Operations Research 31, 223-240.

20: Akimoto Kamiya, Seppo J. Ovaska, Rajkumar Roy, Shigenobu Kobayashi(2004).Fusion of soft computing and hard computing for large-scale plants: a general model, Applied Soft Computing 5 ,265-279.

21: Sh-Tyan Law, Hui-Ming Wee (2006). An integrated production-inventory model for ameliorating and deteriorating items taking account of time discounting, Mathematical and Computer Modeling 43, 673-685.

22: Sh-Tyan Lo, Hui-Ming Wee, Wen-Chang Huang (2006). An integrated production-inventory model with imperfect production processes and Weibull distribution deterioration

Under inflation, Int. J. Production Economics 106 , 248-260.

23: Tulika Chakra borty, B.C. Giri , K.S. Chaudhuri(2008). Production lot sizing with process deterioration and machine breakdown, European Journal of Operational Research 185, 606-618.

24: LI Qun-xia, ZHANG Qun(2008). Optimal Fuzzy Order Inventory Model with a Mixture of Shortages and Imperfect Items, SETP, 28(11), 62-68.

25: M. Rong,N.K. Mahapatra,M. Maiti(2008). A two warehouse inventory model for deteriorating item with partially/fully backlogged shortage and fuzzy lead time, European Journal of Operational Research 189, $59-75$. 
26: Hui-Ming Wee, Chien-Chung Lo, Ping-Hui Hsu(2009): A multi-objective joint replenishment inventory model of deteriorated items in a fuzzy environment, European Journal of Operational Research 197, 620-631.

27: Mark Ko, Ashutosh Tiwari, Jo rn Mehnen(2010): A review of soft computing applications in supply chain management, Applied Soft Computing 10, 661-674.

28: Jui-Jung Liao, Kuo-Nan Huang (2010): Deterministic inventory model for deteriorating items with trade credit financing and capacity constraints, Computers \& Industrial Engineering 59, 611-618.

29: Kung-Jeng Wang, Y.S.Lin , JonasC.P(2011): Optimizing inventory policy for products with timesensitive deteriorating rates in a multi-echelon supply chain, Int. J. Production Economics 130 , 66-76.

30: S.R. Singh ,Tarun Kumar, C. B. Gupta (2011): A Soft Computing based Inventory Model with Deterioration and Price Dependent Demand , International Journal of Computer Applications (0975 - 8887) Volume 36-No.4, December .

31: Monique Bakker, Jan Riezebos, Ruud H. Teunter(2012): Review of inventory systems with deterioration since 2001, European Journal of Operational Research 221 , 275-284.

32: B. Kumar Sett a, Biswajit Sarkar , A. Goswamic(2012): A two-warehouse inventory model with increasing demand and time varying deterioration, Scientia Iranica E,19 (6), 1969-1977.

33: Nita H Shah, Hardik N Soni , Kamlesh A Patel(2013): Optimizing inventory and marketing policy for non-instantaneous deteriorating items with generalized type deterioration and holding cost rates, Omega 41 , $421-430$.

34: N.K. Samal, D.K. Pratihar(2014): Optimization of variable demand fuzzy economic order quantity inventory models without and with backordering, Computers \& Industrial Engineering

35: Yashveer Singh, Kriti Arya, A K Malik (2014): Inventory Control with Soft Computing Techniques, International Journal of Innovative Technology and Exploring Engineering (IJITEE) , 2278-3075.

36: Ata Allah Taleizadeh, Mahsa Noori-daryan, Leopoldo Eduardo Cárdenas-Barrón(2014): Joint Optimization of price, replenishment frequency, replenishment cycle and production rate in vendor managed inventory system with deteriorating items, Int. J. Production Economics.

37: Bibhas Chandra Dasa, Barun Dasb,1, Shyamal Kumar Mondal(2015): An integrated production inventory model under interactive fuzzy credit period for deteriorating item with several markets, Applied Soft Computing 28,453-465.

38: Dogan Ibrahim (2016): An overview of soft computing, Procedia Computer Science $102 \quad, 34$ - 38.

39: Larissa Janssen, Thorsten Claus, Jürgen Sauer (2016): Literature review of deteriorating inventory models, Intern. Journal of Production Economics. 
40: Chi Kin Chan, Wai Him Wong, A. Langevin, Y.C.E. Lee (2017): An Integrated Production-Inventory Model for Deteriorating Items with Consideration of Optimal Production Rate and Deterioration during Delivery, Intern. Journal of Production Economics

41: Li and Zhu (2017): Optimization under uncertainty (2017): A perspective of soft computing, Applied Soft Computing 56,541-542.

42: Snigdha Banerjee, Swati Agrawal (2017): Inventory Model for Deteriorating Items with Freshness and Price Dependent Demand: Optimal Discounting and Ordering Policies, Applied Mathematical Modeling.

43: Yu-Siang Lin, Kung-Jeng Wang (2018): A two-stage stochastic optimization model for warehouse configuration and inventory policy of deteriorating items, Computers \& Industrial Engineering.

44: Marcello Braglia , Davide Castellano , Leonardo Marrazzini , Dongping Song (2019): A continuous review, $(Q, r)$ inventory model for a deteriorating item with random demand and positive lead time, Computers and Operations Research 109, 102-121.

45: Subhash Chandra Das, A.M. Zidan, Amalesh Kumar Manna, Ali Akbar Shaikh, Asoke Kumar Bhunia(2020): An application of preservation technology in Inventory control system with price dependent demand and partial backlogging, Alexandria Engineering Journal 59, 1359-1369. 